that many essential historical episodes have been passed over, but also that certain crucial aspects of the ways in which mathematics aids our search for knowledge are absent. The terms within which the subject has been tackled are too modest, a failing which also applies to the weight of supporting mathematical apparatus which is brought to bear. There is, for example, no discussion of the calculus, so that the "mathematicization" of continuous media and phenomena cannot be described properly. The clash between different mathematical styles is not

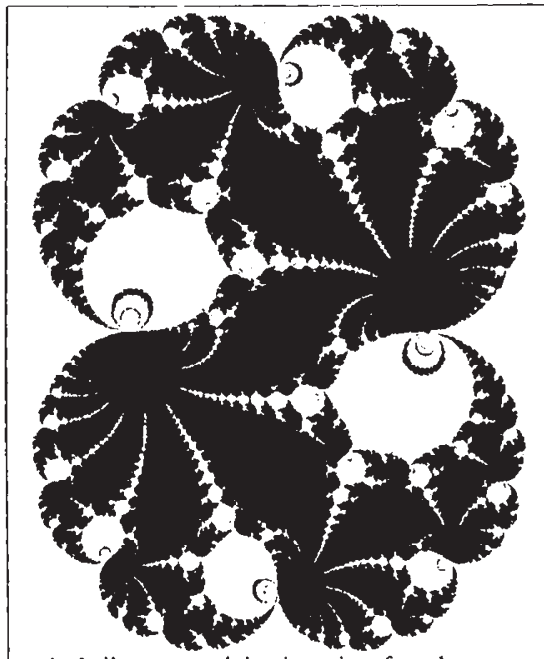

A Julia set and its interior for the map $z \rightarrow z+i \mu$. Taken from Mathematical People (see previous review).

brought out, especially between the geometrical (where the properties of the given configuration play a role) and the algebraic (where formal manipulations of general basic formulae are executed, with deliberate avoidance of geometrical processes); analytical and topological styles bring further differences in their train. Finally, the extent to which a mathematical expression (in any style) reflects the structure of the physical context in which it is used is a matter which should have loomed large, but it does not.

All of these questions involve issues about mathematical proofs, which receive little attention here. But proofs lie at the heart of much of the development of mathematics and thus of its role in the "search for knowledge". The posing of such questions would have served Kline's cause better than the pastiche accounts of philosophers' views on the external world which he does provide (but which have no special bearing on the use of mathematics). This book is best taken as another example of his ability to write breezy and readable surveys of the history of mathematics, and to tackle the philo sophical background on the wing; as a contribution to the problem raised. however. Mathematics and the Search for Knowledge is merely a propaedeutic.

lvor Grattan-Guinness is Reader in Mathematics, Middlesex Polytechnic, Enfield, Middlesex EN3 $4 S F, U K$.

\section{Where lies the science?}

\section{Anthony $W$. Clare}

The Psychoanalytic Movement. By Ernest Gellner. Paladin: 1985. Pp.241. Pbk £3.50. Psychoanalysis and Beyond. By Charles Rycroft. Edited by Peter Fuller. Chatto \& Windus: 1985. Pp.310. Hbk £10.95; pbk 14.95. To be published early next year in the United States by Chicago University Press.

Psychoanalysis: Freud's Cognitive Psychology. By Matthew Hugh Erdelyi. W.H. Freeman: 1985. Pp.303. Hbk \$24.95, $£ 25 ; p b k \$ 14.95, £ 14.95$.

Decline and Fall of the Freudian Empire. By Hans Eysenck. Viking: 1985. Pp.224. £12.95.

TIIE way in which the psychoanalytic school was formed raises profound questions concerning its status as a science and suggests that it might, with benefit, be viewed as a secular religion. Certainly, one will look in vain elsewhere in science for another example of a body of theoretical knowledge linked so intrinsically, so inextricably, with the individual who first propounded it. In no other branch can one find an absence of an external arbitrator, that is to say someone outside the control of the system itself and able to pass independent comment on its claims, achievements and shortcomings. In the case of psychoanalysis, the location of the criterion of its truth is, in the words of Ernest Gellner, "determined by the ideas of the system itself; the well of truth is within the ramparts and not outside". The possession of this truth is not handed down in seminars and courses of instruction, though these play a small part, but by way of participation in the training analysis. As the apostolic succession from St Peter is handed down from the bishops to newly ordained priests, so the authentic link with Freud is maintained and continued by means of the transfer of authority from training analyst to analysand.

The religious analogy does not end there. As intellectual and rational criticism of revealed religious dogma is interpreted as a closing of the mind and heart to truth, and in no way a valid comment on the basic validity of the truth itself, so criticism of psychoanalysis is rejected on the grounds that either the critic has never been analysed, in which case he is resisting the need to be analysed (which itself is worthy of interpretation), or he has been analysed and his criticisms reflect an incomplete or prematurely terminated process. the result no doubt of fear over what might be revealed. And the religious analogy becomes uncomfortable when one examines the schisms and factions within the domain of psychoanalysis, with each school claiming to have adhered the closest to the spirit as well as the law laid down by the supreme founder.

The question which Gibbon asked of Christianity is equally applicable to psychoanalysis: by what means did the new vision obtain so remarkable a victory? In a stylish, witty and deceptively readable book, Gellner exposes the secular religious nature of the psychoanalytic enterprise. He admits that a compelling. charismatic belief must possess more than merely the promise of succour in a plague and links with the background convictions of the age. It must engender a tension in the neophyte or potential convert. It must tease and worry him with its promise and its threat. The doctrine to be embraced must contain the promise of a salvation that is earnestly desired. There must be plausible reasons for believing its claims and also good reasons for doubting it or fearing its truth. The middle ground between acceptance and rejection must be denied and the issue of whether it is or is not true must be trans-empirical and untestable. The fact that confidence in psychoanalysis is devoid of any visible means of support hardly seems to diminish its authority: indeed, argues Gellner.

were its means of support visible, they would be subject to evaluation; and the assertion would have given hostages to fortune, and also conceded its own ordinary, human status - mak ing its own contentions arguable, negotiable. imitable, publicly available rather than tied to a single source.

One psychoanalyst who has been particularly conscious of the contentiousness of the psychoanalytical factions is Charles Rycroft who, in so far as he identifies with any particular school, tends to align him. self with the English-speaking school uniting such disparate practitioners as Winnicott, Fairbairn, Balint and Bowlby. This group, as Rycroft pointed out in an essay entitled "Psychoanalysis and Beyond", contained in the collection of his writings under the same title, repudiated any royal road to becoming an analyst even to the extent of encouraging trainees to have part of their teaching under the supervision of a member of another faction. Rycroft underwent, as far as one can tell, an orthodox Freudian analysis and in 1956 presented a paper to the British PsychoAnalytical Society which challenged the prevailing theory of symbolism by suggesting that it is not a regressive or defensive phenomenon but rather "a general capacity of the mind" which could be deployed in manifold different ways. According to Peter Fuller, the editor of the book, the Society received this modification, the first serious one advanced to a theory of some 40 years standing, with reserve while it struggled to protect the orthodox position. It was the first of a number of theoretically awkward questions that Rycroft was to raise, on such issues as dreams, fantasies and the nature of psychoanalysis itself.

In 1968, he wrote A Critical Dictionary 
of Psychoanalysis, a task which enabled him to take all the current psychoanalytical theories and systems to pieces and compelled him to construct some kind of overview embracing the ideas of Freud and the British analysts - such as Anna Freud. Melanie Klein. Michael Balint and Donald Winnicott - who had been active when he himself had been a student. His growing conviction that psychoanalysis is not so much concerned with the causes of human behaviour as with its meaning, and is better seen as one of the humanities than a science, does enable him to side-step many of the objections to psychoanalysis made by those such as Gellner and. as we shall see. Eysenck. However. nowhere in the 25 essays contained in this collection does he apply his mind to the issue which clearly troubles critics. namely the extent to which psychoanalysis is a self-fulfilling explanatory theory. whether it be of meaning or causes.

Meanwhile. there are others such as Professor Erdelyi, of the Department of Psychology at Brooklyn College, who struggle to salvage as much of Freud's expansive theory as modern insights in cognitive, physiological and neurological psychology will permit. Erdelyi's book uses case histories, laboratory studies, newspaper cuttings, visual art and poetry in an imaginative if occasionally wayward examination of Freudian theory. What emerges, however, suggests that what was lasting in Freud's conceptions is their general preoccupations. The specific elements of that gigantic canvas - the separation of mental functioning into id, ego, superego, theories of dream function and the nature of repression - just do not stand up to the relentless scrutiny of the laboratory scientists or the critical clinician. A particularly good example concerns Freud's pleasure principle. Freud assumed that pleasure/positive reinforcement resulted from tension-drive reduction; that, in short, pleasure was the cessation of pain - the so-called "Nirvana principle". The physiological facts suggest otherwise. Pleasure and unpleasure appear to be not opposite sides of the same coin but two different coins altogether. More uncomfortable for psychoanalysts is the fact that the "pleasure" arising from stimulation of the pleasure centre in the brain is general in nature and not sexual as a great deal of psychoanalytical writing and excavation argues.

The most fundamental criticism of psychoanalysis, however, remains the same. 30 years on from when Hans Eysenck first mounted it. It is the fact that there is no convincing evidence that patients do better under analyses than they do under some other form of psychotherapy or psychiatric treatment. Such criticism does not come only from without. Anthony Storr. himself a Jungian analyst, has concluded that "the evidence that psychoanalysis cures anyone of anything is so shaky as to be practically non-existent". And Brian Farrell, a philosopher by no means hostile to analysis, has admitted that the impact of psychoanalysis

cannot be justified on the grounds that it contains a body of reasonably secure or established knowledge . . . it [is] only too painfully evident that analysis does not contain any such body of knowledge.

Characteristically, Eysenck puts the case with more exuberance and venom. At best, he concludes his devastating polemical assault. psychoanalysis is "a premature crystallization of spurious orthodoxies; at worst a pseudo-scientific doctrine that has done untold harm to psychology and psychiatry alike". The final verdict, however, is not in and it is doubtful that it will be within the lifetimes of the authors of these books. What does seem unarguable, however, is that in the one hundred years that have passed since Freud began to build his theoretical framework the theory still lacks any substantial validity and his school remains beleaguered.

Anthony $W$. Clare is Professor in the Department of Psychological Medicine, St Bartholomew's Hospital Medical College, West Smithfield, London ECIA $7 B E, U K$.

\section{IMAGE \\ UNAVAILABLE FOR COPYRIGHT REASONS}

\section{Scent of semi-science}

\section{Steve Blinkhorn}

The Intelligence Men: Makers of the IQ Controversy. By Richard E. Fancher. $W$. W. Norton: 1985. Pp.269. \$17.95, £14.95.

AT l.AST, it seems, the soot and whitewash school of controversy has had its day. Here is a book about the IQ debate which is at once absorbing. informative, deftly written and, if the expression can be pardoned. a thundering good read.

The Intelligence Men is that rare inversion of the natural order of things: a firstrate book based on a second-rate notion. The notion. that one may discover why particular figures in the history of a debate took up their respective positions by examining their personal histories, is only as good as the sample of biographical material available and the accuracy with which it is interpreted; in any case, the standards of proof required of such a notion are far inferior to those proper to the debate itself. Fortunately analysis of this sort intrudes very little into Fancher's account of the lives and work of a dozen or so major contributors to the long-running dispute over IQ.

The delicious consequence of this plan has been a book reeking of the dubious scent of semi-science in the making. Where often a scientist is known to a wider public only as an author of published work, here that work is set in a personal context which illuminates and informs even when the technical level of the narra. tive is less than satisfactory. Pasteboard textbook characters have pasteboard theories to peddle. But the facts that Spearman registered for a $\mathrm{PhD}$ with Wundt (and took seven years to complete it), that Terman's introduction to psychology was a book on phrenology and that amongst Yerkes's motivations for seeking a career as a physician was the fact that it paid better than being a farmer, bring an unusual sparkle to academic history.

Kamin's brush with McCarthy's subcommittee on unAmerican activities; Jensen's origins as the son of a lumber and building-supplies dealer, and habit of conducting recorded symphonies at home with a chopstick for a baton; Binet as a child being forced by his father to touch a cadaver; Burt labouring to devise raw data to fit published statistics - none of this is relevant to the logic of scientific discovery. But, as Fancher suggests, the psychology of the scientist is at least as potent a force in determining the direction of theory. This, of course, is a view that can be taken to extremes. There was once a claim that Spearman, being British and therefore a monarchist, was driven to expect a single factor of intelligence, whereas Thurstone, being American and more democratically inclined, preferred a federalist view with several distinct abili- 